\title{
Maternal outcome in obstetric ICU and HDU: a study from a teaching hospital in South India
}

\author{
Vinutha K. Veerabhadrappa ${ }^{1}$, Mamatha Shivanagappa ${ }^{1 *}$, \\ Mahesh Mahadevaiah' ${ }^{2}$, Sujatha M. Srikanth ${ }^{1}$
}

\begin{abstract}
${ }^{1}$ Department of Obstetrics and Gynecology, ${ }^{2}$ Department of General Medicine, JSS Medical College, JSS Academy of Higher Education and Research (deemed to be University), Mysore, Karnataka, India
\end{abstract}

Received: 05 February 2019

Accepted: 15 February 2019

\section{*Correspondence:}

Dr. Mamatha Shivanagappa,

E-mail: mamathamahesh106@gmail.com

Copyright: () the author(s), publisher and licensee Medip Academy. This is an open-access article distributed under the terms of the Creative Commons Attribution Non-Commercial License, which permits unrestricted non-commercial use, distribution, and reproduction in any medium, provided the original work is properly cited.

\begin{abstract}
Background: The management of critically ill obstetric patients presents a unique challenge. Dedicated High Dependency Unit (HDU) and Intensive Care Unit (ICU) for obstetric patients are widely available in India. The data regarding obstetric critical care is invaluable in formulating policy decisions. The objective is to study the profile of cases admitted to obstetric HDU and ICU and to evaluate maternal outcome and co-morbid conditions.

Methods: This was a prospective observational study between January 2017 and June 2018.

Results: Total number of obstetric admissions was 7966. Total admissions to obstetric ICU were 60. ICU cases accounted for $0.7 \%$ of all obstetric admissions and $1.1 \%$ all deliveries. Obstetric cases formed $1.6 \%$ of total ICU admissions. Number of admissions to HDU was 576. HDU cases accounted for $7.2 \%$ of all obstetric admissions. HDU utilization rate was $11.32 \%$. Hypertensive disorders of pregnancy $(n=22,33.3 \%)$, obstetric haemorrhage ( $n=18$, $30 \%)$, septic abortion $(\mathrm{n}=2,3.3 \%)$ were the most common conditions necessitating admission.

Conclusions: Hemorrhage was the most common indication for admission to HDU. Delayed identification and referral were the important obstacles. There is a need for early booking at peripheral centres. Introduction of obstetric ICU and multidisciplinary approach has brought down the incidence of maternal mortality in present centre.
\end{abstract}

Keywords: Critical care obstetrics, Intermediate obstetric unit, Maternal morbidity

\section{INTRODUCTION}

Everyday approximately 830 women die from preventable causes related to pregnancy and childbirth. ${ }^{1}$ Despite significant improvements in obstetric care over the last few decades maternal mortality continues to be a major challenge in the developing world. ${ }^{2}$ The timely recognition of complications and appropriate management at a comprehensive emergency obstetric care setting would improve maternal health outcomes. The concept of obstetric critical care is yet to gain strong foot hold in developing countries. Dedicated ICU for obstetric patients is not yet widely available. Dedicated HDU/ICU is necessary in India because public health facilities do not have a separate special care unit for high risk pregnancies and postpartum mothers with complications. ${ }^{3}$

Reviewing critical cases can provide significant information about areas of improvement and is useful in identifying health system failures and assessment of quality of maternal health-care. ${ }^{4}$ The available data from India in this regard is very limited more so from South India. Hence this study was taken up. 
The objective is to study the profile of cases admitted to obstetric HDU and ICU and evaluate the maternal outcome. The study also aimed to evaluate the co morbid conditions associated and aggravated during pregnancies.

\section{METHODS}

This was a prospective observational study conducted at JSS Medical College and Hospital, a tertiary care referral centre January 2017 to June 2018. The hospital is well equipped with 2800 inpatient beds and 280 ICU beds serving adults and 40 ICU beds serving neonates.

\section{Inclusion criteria}

- All women admitted to HDU and ICU either due to obstetric or co morbid conditions were included in the study.

\section{Exclusion criteria}

Pregnant women admitted for:

- Treatment of poisoning

- Road traffic accident

- Other medico-legal cases and

- Those who expired within four hours were excluded from the study.

The relevant data collected according to proforma was analysed with respect to patient characteristics, obstetric history, pre-existing medical disorders and the causes that necessitated admission to the HDU and ICU. These were identified as preeclampsia, eclampsia, haemorrhage, sepsis, and respiratory failure. The duration of the ICU stay and the specific interventions that had been undertaken at the ICU (such as the use of intubation, mechanical ventilation, and intensive monitoring; dialysis, and plasmapheresis, the use of fresh frozen plasma, packed erythrocytes, and platelets; and the use of vasoactive infusions, the use of fibrinogen infusions; and the use of antibiotics) were recorded. The complications that were encountered at the ICU, such as disseminated intravascular coagulation (DIC) and multiorgan failure, were recorded.

The diagnosis of DIC required a low platelet count (b100 $\times 109 / \mathrm{L})$, a low fibrinogen level (b3mg/L), a prolonged prothrombin time (N14 seconds), a high international normalized ratio level (N1.3), and a prolonged partial thromboplastin time (N40 seconds). Multiorgan failure was defined as the failure of 3 or more critical physiological systems, including the respiratory system, the cardiovascular system, the nervous system, the hepatobiliary system, or the urinary system. The maternal deaths were recorded, and the maternal mortality rate was calculated. The study details was presented before the
Ethical Committee of JSS Medical College and was approved thereof.

\section{Statistical analysis}

Categorical and continuous variables are expressed as number (percentage) and mean \pm standard deviation respectively. Chi square was applied to compare categorical variables and student's t test was used to compare parametric continuous variables. The data was analyzed using SPSS software version 21 and a p value of $<0.005$ was considered significant.

\section{RESULTS}

The total number of obstetric admissions was 7966. The total number deliveries were 5085 of which the number of live births was 4490. There were 8 maternal deaths during the study period. The maternal mortality ratio was $1.7 / 1000$ deliveries.

With reference to obstetric ICU the data were as follows. The total admissions were 60. ICU cases accounted for $0.7 \%$ of all obstetric admissions and $1.1 \%$ all deliveries. ICU utilization rate was $0.7 \%$. Amongst the 60 subjects, $32(53 \%)$ were admitted directly, another 14 (23\%) were shifted from Operation Theatre and the rest $14(23 \%)$ were shifted from HDU. Obstetric cases formed $1.6 \%$ of total ICU admissions. Of the 60 women $52(86.7 \%)$ were survivors and $8(13.3 \%)$ were non-survivors.

There was no significant difference between the survivors and non survivors in terms of age. About $92 \%$ of the patients were referred from outside $(\mathrm{p}<0.01)$. Amongst non survivors all were referred from surrounding five districts. No mortality was seen in those who had been booked at present centre.

More than $78 \%$ of the women were from places beyond $50 \mathrm{~km}$ of distance. No significant difference was seen between the two groups with respect to literacy status and distance from the centre. Majority of the women admitted to ICU were primiparous $(58 \%)$ and $25 \%$ of women were in their second pregnancy. Increasing parity was associated with increased risk of mortality $(\mathrm{P}<0.05)$.

Post-partum admissions ( $\mathrm{n}=47,78 \%$ ) were significantly more as compared to ante-partum admissions $(n=13$, $22 \%$ ). The mean gestational age was $32.3 \pm 5.5$ weeks. $32 \%$ of women were in the group of $>37$ weeks and $43 \%$ of women were between $28-36$ weeks. $15 \%$ of the cases were less than 20 weeks of gestation.

Nearly $70 \%$ patients admitted had BMI in the range of $19-23$ and $30 \%$ of the patients were overweight or obese. $23.3 \%$ of the women were severely anaemic and $16 \%$ of women were moderately anaemic. 
Table 1: Demographic and baseline clinical characteristics of women admitted to ICU.

\begin{tabular}{|c|c|c|c|c|}
\hline \multicolumn{2}{|c|}{ Characteristic feature } & \multirow{2}{*}{$\begin{array}{l}\text { Total }(\%) \\
60\end{array}$} & \multirow{2}{*}{$\begin{array}{l}\text { Survivors (\%) } \\
52(86.2)\end{array}$} & \multirow{2}{*}{$\begin{array}{l}\text { Non survivors (\%) } \\
8(13.8)\end{array}$} \\
\hline No. of patients & & & & \\
\hline \multirow{3}{*}{ Age in years } & Mean \pm SD (years) & $24.2 \pm 0.6$ & $24.6 \pm 3.4$ & $23.8 \pm 3$ \\
\hline & $19-29$ & $56(93.3)$ & $48(80)$ & $8(10.3)$ \\
\hline & $>30$ & $4(6.7)$ & $4(6.7)$ & 0 \\
\hline \multirow{4}{*}{ Parity } & $\mathrm{P} 1$ & $35((58.3)$ & $30(50)$ & $5(8.3)$ \\
\hline & $\mathrm{P} 2$ & $15(25)$ & $14(23.3)$ & $1(1.7)$ \\
\hline & P3 & $7(11.7)$ & $7(11.7)$ & 0 \\
\hline & $\mathrm{P} 4$ & $3(5)$ & $1(1.7)$ & $2(3.3)$ \\
\hline Postpartum & & $47(78.3)$ & $40(66.7)$ & $7(11.6)$ \\
\hline Antepartum & & $13(21.7)$ & $12(20)$ & $1(1.7)$ \\
\hline \multirow{5}{*}{ Gestational age } & Mean \pm SD (weeks) & $32.3 \pm 5.5$ & $28.4 \pm 11.9$ & $36.1 \pm 2.3$ \\
\hline & $<20$ weeks & 9 & 8 & 1 \\
\hline & 21-27 weeks & 2 & 2 & 0 \\
\hline & 28-36 weeks & 20 & 17 & 3 \\
\hline & $>36$ weeks & 15 & 11 & 4 \\
\hline \multirow{3}{*}{ BMI } & $19-23$ & $42(70)$ & $36(60)$ & $6(10)$ \\
\hline & $24-29$ & $15(25)$ & $14(23.3)$ & $1(1.7)$ \\
\hline & $>30$ & $3(5)$ & $2(3.3)$ & $1(1.7)$ \\
\hline \multirow{5}{*}{ Haemoglobin } & $<4$ & $2(3.3)$ & 2 & 0 \\
\hline & $<7$ & $12(20)$ & 12 & 0 \\
\hline & $7-10$ & $10(16.6)$ & 10 & 4 \\
\hline & $10-11$ & 7 (11.6) & 7 & 0 \\
\hline & $>11$ & $29(48.3)$ & 25 & 4 \\
\hline
\end{tabular}

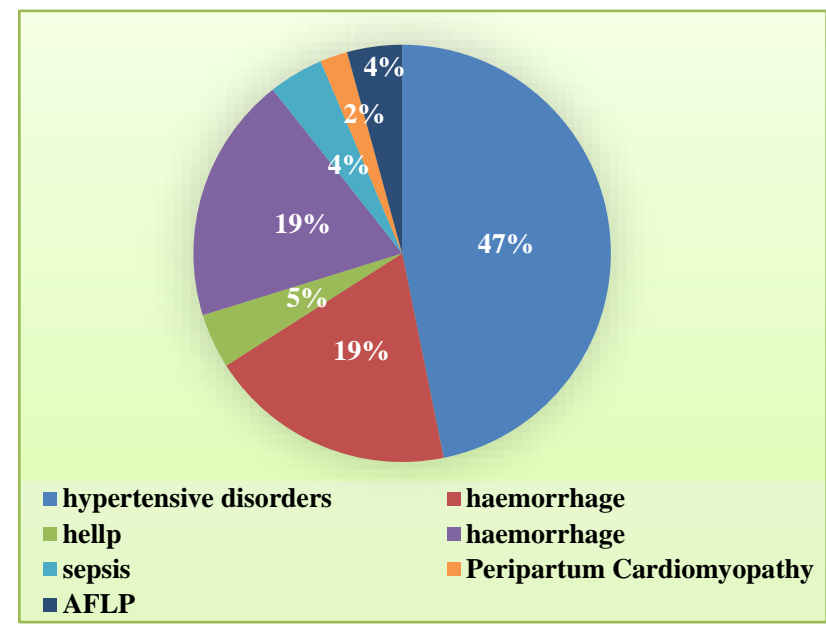

Figure 1: Obstetric causes leading to ICU admissions.

The various conditions necessitating ICU admissions are shown in Figure 1 and 2. The most common conditions which necessitated ICU admission included Hypertensive disorders of pregnancy $(\mathrm{n}=22,33.3 \%)$, Obstetric Haemorrhage $(n=18,30 \%)$, Septic abortion $(n=2,3.3 \%)$. Authors had a significant number of women $(n=8,13.3 \%)$ with ruptured ectopic with haemodynamic instability necessitating ICU admission. Various complications included DIC, Pulmonary Edema, MODS. The most common non obstetric causes included cardiac disease $(n=9,15 \%)$, febrile illness $(n=4,6.7 \%)$, respiratory illness $(n=3,5 \%)$. Around $10 \%$ of women has more than one complication necessitating ICU admission. Around 5\% of them had two complications and about $4 \%$ had three complications. Anaemia was associated in one third of women of which $20 \%(n=12)$ were severely anaemic. The common pre-existing conditions were cardiac diseases $(\mathrm{n}=6,10 \%)$, bronchial asthma $(\mathrm{n}=3,5 \%)$.

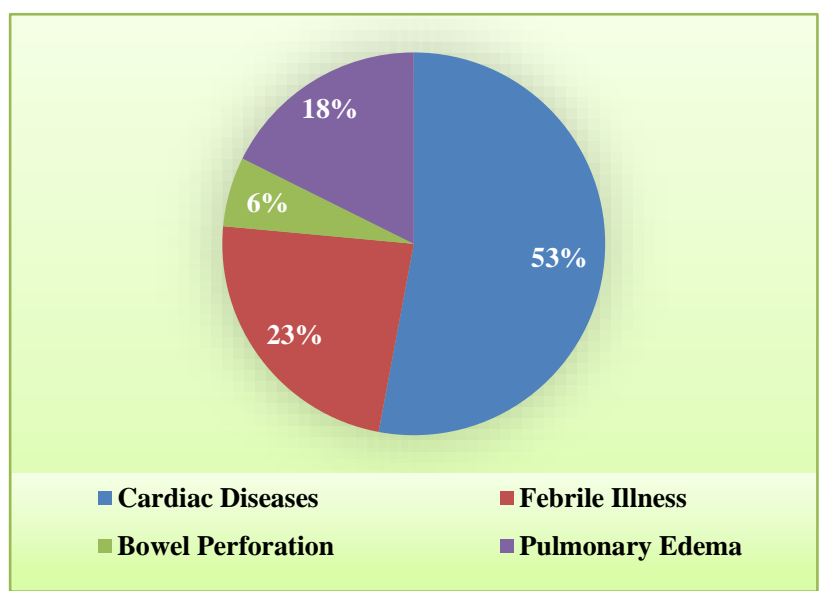

Figure 2: Non obstetric causes.

The various interventions carried out are details in Table 2 and Figure 3. 21.6\% $(n=13)$ of women were managed conservatively. The most commonly performed surgical intervention was LSCS in $53.3 \%(\mathrm{n}=32)$ of the women followed by salpingectomy $(n=8,13.3 \%) .38 \%$ of patients required blood and blood products. $36 \%$ required 
inotropic support and $51 \%$ were on mechanical ventilation.

Table 2: Distribution of patients according to various interventions given.

\begin{tabular}{|c|c|c|c|}
\hline Intervention & $\begin{array}{l}\text { Total } \\
\text { n (\%) }\end{array}$ & Survivors & $\begin{array}{l}\text { Non } \\
\text { survivors }\end{array}$ \\
\hline \multicolumn{4}{|c|}{ Blood and blood products transfusion } \\
\hline PRBC & $23(38.3)$ & 21 & 2 \\
\hline$<5$ units & 17 & 16 & 1 \\
\hline$>5$ units & 6 & 5 & 1 \\
\hline FFP & $28(46.6)$ & 21 & 7 \\
\hline PRP & $23(38.3)$ & 16 & 7 \\
\hline Ventilator support & $31(51.6)$ & 26 & 5 \\
\hline Inotrope support & $36(60)$ & 29 & 7 \\
\hline Dialysis & $4(6.6)$ & & 4 \\
\hline
\end{tabular}

With regards to Obstetric HDU the number of admissions to HDU was 576. The total number of obstetric admissions was 7966 during the study period. HDU cases accounted for $7.2 \%$ of all obstetric admissions and $88 \%$ of near miss cases. HDU utilization rate was $11.32 \%$. Amongst the 576 women $321(55.7 \%)$ were admitted directly, another 176 (30.5\%) were shifted from Operation Theatre and the rest $79(13.8 \%)$ were shifted from wards.

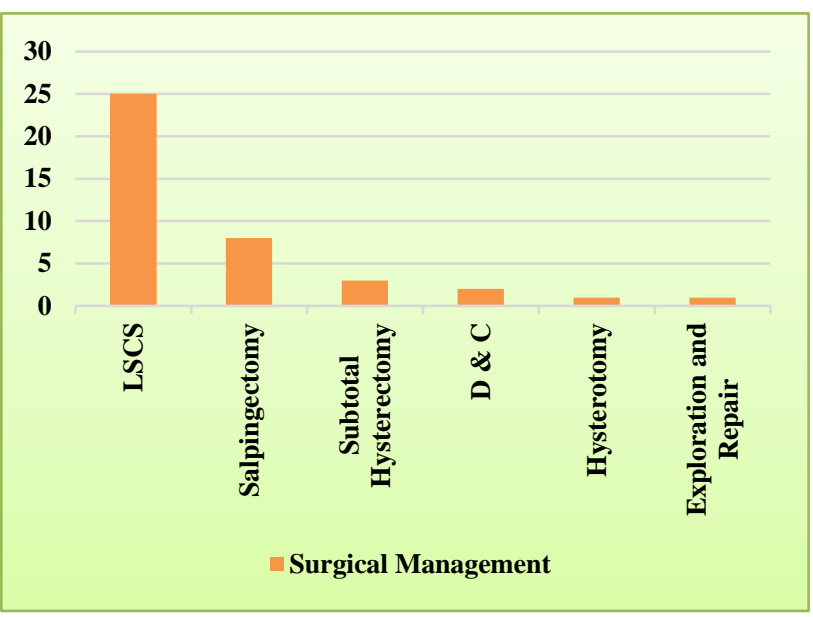

Figure 3: Surgical management.

The demographic and clinical details of women admitted to HDU are depicted in Table 3. The mean age of the patients admitted to HDU was 26 years $(26 \pm 5)$. The minimum and maximum age of pregnant women was 18 years and 44 years respectively. About $24 \%$ of women were in the age group of more than 30 years. About $69.9 \%(n=403)$ of the patients were referred from outside $(p<0.01)$. Around $30.4 \% \quad(n=175)$ of the women were from places beyond $50 \mathrm{~km}$ of distance. More than $89 \%$ of women were literate. $51 \% \quad(n=296)$ of the women admitted to HDU were primiparous. $26.9 \%(n=155)$ of women were in their second pregnancy. $14.5 \%(n=84)$ of women were in their third pregnancy. Increasing parity was associated with increased morbidity $(\mathrm{P}<0.05)$.
Antepartum admissions ( $\mathrm{n}=396,69 \%)$ were significantly more as compared to post-partum admissions $(\mathrm{n}=180$, $31 \%$ ). The mean gestational age was $30.7 \pm 9.9$ weeks. $31.7 \% \quad(n=183)$ of women were in the group of $>37$ weeks of gestation and $37.2 \%(n=215)$ of women were in the gestational age between $28-36$ weeks. $13.7 \%$ of the cases were less than 20 weeks of gestation. Nearly $63.1 \%$ $(\mathrm{n}=364)$ patients admitted had BMI in the range of 19-23 and $37 \%$ of the patients were overweight or obese. $7.6 \%$ $(n=44)$ of the women were severely anaemic and $26 \%$ $(n=154)$ of women were moderately anaemic.

Table 3: Demographic characteristics of patients admitted to HDU.

\begin{tabular}{|c|c|c|}
\hline \multicolumn{2}{|c|}{ Characteristic feature } & Total n (\%) \\
\hline No. of patients & & 576 \\
\hline \multirow{3}{*}{ Age in years } & Mean \pm SD (years) & $26 \pm 5$ \\
\hline & $<30$ & $439(76.2)$ \\
\hline & $>30$ & $137(23.8)$ \\
\hline \multirow{6}{*}{ Parity } & $\mathrm{P} 1$ & $276(47.9)$ \\
\hline & $\mathrm{P} 2$ & $147(25.5)$ \\
\hline & P3 & $81(14)$ \\
\hline & $\mathrm{P} 4$ & $21(3.6)$ \\
\hline & P5 & $7(0.92)$ \\
\hline & $\mathrm{P} 7$ & $1(0.01)$ \\
\hline Antepartum & & $396(68)$ \\
\hline Postpartum & & $180(32)$ \\
\hline \multirow{4}{*}{ Gestational age } & $<20$ weeks & $79(15)$ \\
\hline & 21-28 weeks & $47(8.9)$ \\
\hline & 28-36 weeks & $215(41)$ \\
\hline & >37 weeks & $183(34.9)$ \\
\hline \multirow{3}{*}{ BMI } & $19-23$ & $364(63.1)$ \\
\hline & $24-29$ & $184(31.9)$ \\
\hline & $>30$ & $28(4.8)$ \\
\hline \multirow{4}{*}{ Haemoglobin } & $<7$ & $44(7.6)$ \\
\hline & $7-10$ & $154(26.7)$ \\
\hline & $10-11$ & $146(23.3)$ \\
\hline & $>11$ & $232(40.2)$ \\
\hline
\end{tabular}

The conditions necessitating HDU admission are depicted Figure 4. The most common conditions which necessitated HDU admission included Hypertensive disorders of pregnancy $(\mathrm{n}=301,52.2 \%)$, Obstetric Haemorrhage $(n=135,23.4 \%)$, Septicaemia ( $n=6,1 \%)$. Ruptured ectopic with haemodynamic instability was found in $(n=50,8.6 \%)$. The most common non obstetric causes included cardiac disease $(n=27,4.6 \%)$, uncontrolled gestational diabetes mellitus $(n=22,3.8 \%)$, febrile illness $(n=13,2.2 \%)$. Around $10 \%$ of women had more than one complication and $5 \%$ developed multiple complications and were transferred to ICU.

Anaemia was associated in $33.6 \%(\mathrm{n}=194)$ of women of which $7.6 \% \quad(n=44)$ were severely anaemic. 25 women had pre existing cardiac illness in the form of rheumatic heart disease $(n=18)$ and congenital heart disease $(n=9) .8$ women had epilepsy disorder. $76(13.1 \%)$ women had previously undergone caesarean section. 


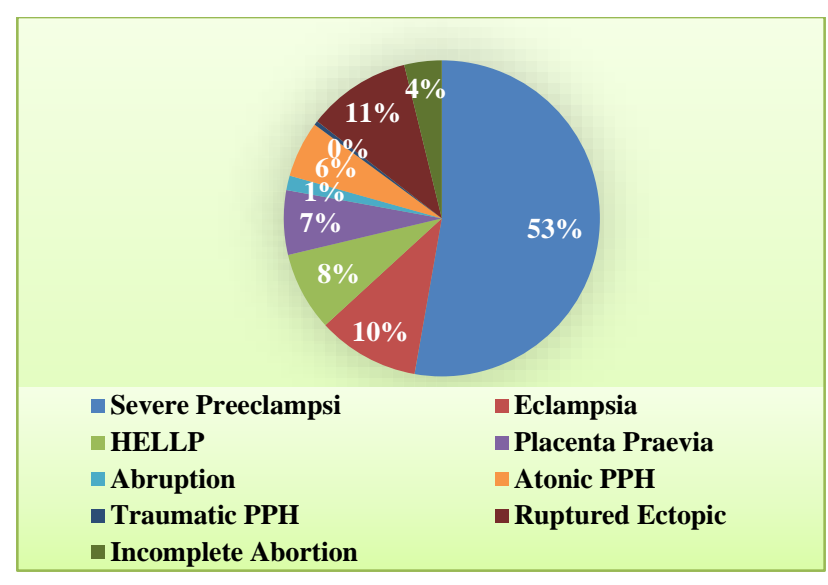

Figure 4: Causes of HDU admission.

With regard to intervention $13.7 \%(n=79)$ of women were managed conservatively and the rest had to undergo some form of surgical intervention. The number of vaginal deliveries was $13(2.2 \%)$. The most commonly performed intervention was caesarean section $(57.6 \%, \mathrm{n}=332)$. Other procedures included salpingectomy $(8.6 \%, \mathrm{n}=50), \mathrm{D}$ and C $(3.6, n=21)$, expulsion $(9.7 \%, n=56)$, assisted vaginal delivery $(0.86 \%, \mathrm{n}=5)$, subtotal hysterectomy $(0.86 \%$, $\mathrm{n}=5)$, exploration and repair $(0.52 \%, \mathrm{n}=3)$, manual removal of placenta $(0.52 \%, \mathrm{n}=3)$, hysterotomy $(0.1 \%$, $\mathrm{n}=1) .43 \%(\mathrm{n}=248)$ of patients required blood and blood products in the form of PRBC $(n=118)$, FFP $(n=116)$ and platelets $(\mathrm{n}=111)$.

\section{DISCUSSION}

The present study included analysis of women admitted to obstetric critical care units (HDU and ICU) and their outcome. The ICU admission rate in present study was $0.7 \%$ which is similar to the 0.1 to $0.9 \%$ reported in different studies. ${ }^{5,6} \mathrm{~A}$ few other studies have reported a higher ICU admission rates. ${ }^{7,8}$ The lower ICU admission rate in present study could be attributed to well functioning HDU and timely screening for complications and their management. The other cause could be differences in patient characteristics and as well as the differences in the ICU admission criteria. Obstetric cases formed $1.6 \%$ of overall ICU admissions. In some studies, obstetric cases formed $2-7 \%$ of all ICU admissions. ${ }^{9}$ Obstetric ICU designed specifically for pregnant and post-partum women was not available in present centre. There is definitely a requirement for a dedicated obstetric ICU.

The maternal mortality is only the tip of an iceberg, the actual burden being much higher. ${ }^{7}$ The recent focus has been towards provision of comprehensive emergency obstetric care in the form of HDU and ICU. The ministry of health and family welfare has released guidelines for setting up and operating HDU in the country. ${ }^{3}$ Currently the availability of data with regard to profile of women admitted to HDU is limited in our country. The availability of ICU beds is a challenge in a developing country like India. The HDU admission rate is $7.2 \%$ of all obstetric admission and $11.32 \%$ of all deliveries. There is not much data available with regard to HDU admission rates. Going by data published in other countries the rate is a rough predictor for planning in case of tertiary centres.

Majority of the admission were post partum in obstetric ICU whereas majority of admission in obstetric HDU were ante-partum. This finding is consistent with other similar studies of ICU and HDU admissions. ${ }^{8}$ The most common conditions for all obstetric ICU admissions included pregnancy related hypertensive disorders followed by haemorrhage and sepsis. This is in consistent with findings of other studies done in intensive care settings. ${ }^{9-11}$ However certain other studies have reported haemorrhage as the most common cause of ICU admission. ${ }^{12}$ A Few studies done in the Indian setting have reported haemorrhage as the important cause of ICU admission while others have noted pregnancy related hypertensive complications to be the most important cause. ${ }^{13,14}$ The higher rate of obstetric compared to medical complications is consistent with findings of other studies.

Authors observed a higher number of cases of ruptured ectopic being admitted to ICU compared to previous studies. Severe anemia was a predictor of ICU admissions in these patients. It calls for early detection and management of such cases so that more serious complications like rupture can be avoided. Of 44 survivors 7 had residual end organ failure which needed prolonged treatment and involvement of multidisciplinary team. Gestational diabetes was found in $2.2 \%$ of women with risk of adverse maternal and neonatal outcome. With the rise in incidence of obesity and advanced maternal age this would pose a greater challenge in future in obstetric care.

The state of pregnancy unmasks or worsens the underlying co morbidities. It is not uncommon to detect an underlying rheumatic heart disease or congenital heart disease during pregnancy. Authors had a significant number of women admitted to HDU and ICU because of non obstetric causes. Acute febrile illness (like dengue, malaria) formed about $6 \%$ of all cases admitted to HDU and ICU carried a significant risk of mortality. It calls for multidisciplinary approach and advanced mean of monitoring. Many studies have found cardiac diseases to be a significant contributor for non obstetric related mortality. ${ }^{15,16}$ Authors had 27 Cases of cardiac diseases of which two did not survive. The management of some of these cases is extremely complex and requires a multidisciplinary team with appropriate expertise. In future non obstetric complication need focussed attention because of high risk of mortality.

Caesarean section was the most common intervention in present study. The higher rate of caesarean sections seen in present study could be because of higher number of 
complicated cases referred in late stages. Studies have found prior history of Caesarean a risk factor for developing maternal near miss. ${ }^{17}$ The number of vaginal deliveries was 38. Authors had 58 women undergoing salpingectomy for ruptured ectopic. The other surgical interventions carried out were exploration and repair and subtotal hysterectomy.

There was a total of 8 maternal deaths in the ICU during the study period. There were an additional 10 deaths which occurred outside ICU like in emergency outpatient areas, during transfer and in Operation theatre the details of which were not analysed as it was not the within the purview of present study. There were no deaths which occurred in HDU. The incidence of ICU mortality rate in present study was $13.3 \%$. This is lower than $15-20 \%$ ICU mortality rate reported in various studies. ${ }^{18,19}$ A well functioning HDU contributed to a low mortality rate in ICU. The mortality rate in present study was $1.7 / 1000$ live births. The rate higher in comparison to other studies in developed countries. ${ }^{20}$ Present centre being a tertiary care hospital majority of the women had severe complications and many were referred after a significant amount of delay. This emphasizes the point that there may not be much time for transfer to ICU in case of obstetric cases and things can turn for the worse pretty quickly. Lack of antenatal care, poor socio economic background, delays in referral from the peripheral health centres predicted poor outcomes.

Strengths: The study included a relatively a large number compared to similar studies conducted in the Indian context. The study sample consisted of varied cases and at various stages of presentation. The study evaluated maternal outcome as a continuum, ranging from severe morbidity, near miss events and ultimately to maternal death. There are not many Indian studies analyzing the patients admitted to HDU. The present study is unique in respect of analyzing the whole spectra of patients requiring HDU admission, ICU admission and near miss cases.

Limitations: However, this study did not include in-depth interviews of the women with near-misses about factors related to social determinants and their experiences of accessing and receiving care which is practice in some countries. ${ }^{20}$ Authors did not use any alternate scoring system such as simplified acute physiology score (SAPS), acute physiology and chronic health evaluation (APACHE), and mortality probability models (MPM) for predicting the severity of maternal outcome.

\section{CONCLUSION}

The study highlights importance of having on site access to HDU and ICU in effectively managing and preventing morbidity in critically ill obstetric patients. Early detection should be followed by early action, management and escalation. HDU acts as step up or step down between labour ward and critical care services and is safe and effective when coupled with rapid access to ICU.

\section{ACKNOWLEDGMENTS}

Authors would like to thank the various clinical staff of Critical Care, Internal Medicine, Nephrology for their assistance in patient management. Authors are grateful to Dr. Santhosh Shivabasappa for his additional assistance in manuscript preparation. Authors wish to express their sincere thanks to Dr. Yathish HM, Assistant Professor Department of Genetics, Veterinary College, Bengaluru for help in statistical analysis.

\section{Funding: No funding sources}

Conflict of interest: None declared

Ethical approval: The study was approved by the Institutional Ethics Committee

\section{REFERENCES}

1. World Health Organization. Trends in Maternal Mortality: 1990 to 2015: Estimates by WHO, UNICEF, UNFPA, World Bank Group and the United Nations Population Division. Geneva: World Health Organization; 2015.

2. Maternal Mortality Estimates developed by WHO, UNICEF and UNFPA. Geneva, World Health Organization, 2004.

3. Guidelines for obstetric HDU and ICU. Ministry of Health and Family Welfare, March 2016.

4. Dattaray C, Mandal D, Shankar U, Bhattacharya P, Mandal S. Obstetric patients requiring highdependency unit admission in a tertiary referral centre. Int J Crit Illn Inj Sci. 2013;3(1):31-5.

5. Okafor UV, Efetie ER. Critical care obstetrics in a developing country. J Turk Ger Gynecol Assoc. 2008;9:9-13.

6. Gilbert TT, Smulian JC, Martin AA, Ananth CV, Scorza W, Scardella AT. Obstetric admissions to the intensive care unit: outcomes and severity of illness. Obstet Gynecol. 2003;102(5 Pt 1):897-903.

7. WHO systematic review of maternal morbidity and mortality: the prevalence of severe acute maternal morbidity (near miss). Reproductive Health 2004, 1:3 doi:10.1186/1742-4755-1-3.

8. Gupta S, Naithani U, Doshi V, Bhargava V, Vijay BS. Obstetric critical care: A prospective analysis of clinical characteristics, predictability, and fetomaternal outcome in a new dedicated obstetric intensive care unit. Indian J Anaesth. 2011;55(2):146-53.

9. Keizer JL, Zwart JJ, Meerman RH, Harinck BI, Feuth HD, van Roosmalen J. Obstetric intensive care admissions: a 12-year review in a tertiary care centre. Europ J Obstet Gynecol Reprod Biol. 2006;128(12):152-6.

10. Demirkiran O, Dikmen $\mathrm{Y}$, Utku T, Urkmez S. Critically ill obstetric patients in the intensive care unit. Int J Obstet Anesth. 2003;12:266-70. 
11. Waterstone M, Bewley S, Wolfe C. Incidence and predictors of severe obstetric morbidity: case-control study. BMJ. 2001;322:1089-93.

12. Tang LC, Kwok AC, Wong AY, Lee YY, Sun KO, So AP. Critical care in obstetrical patients: an eightyear review. Chin Med J. 1997;110:936-41.

13. Jain S, Guleria K, Vaid NB, Suneja A, Ahuja S. Predictors and outcome of obstetric admissions to intensive care unit: A comparative study. Indian J Public Health. 2016;60(2):159-63.

14. Chhabra P, Guleria K, Saini NK, Anjur KT, Vaid NB. Pattern of severe maternal morbidity in a tertiary hospital of Delhi, India: A pilot study. Trop Doct. 2008;38:201-4.

15. Vasquez DN, Estenssoro E, Canales HS, Reina R, Saenz MG, Das Neves AV, et al. Clinical characteristics and outcomes of obstetric patients requiring ICU admission. Chest. 2007;131:718-24.

16. Saravankumar K, Davies L, Lewis M, Cooper GM. High dependency care in obstetric setting in the UK. Anaesthesia. 2008;63:1081-6.

17. Pattinson R, Say L, Souza J, van den Broek N, Rooney C. WHO working group on maternal mortality and morbidity classification. Bull World Health Organ. 2009;87(10):734.

18. Leung NY, Lau AC, Chan KK, Yan WW. Clinical characteristics and outcomes of obstetric patients admitted to the Intensive Care Unit: A 10-year retrospective review. Hong Kong Med J. 2010;16:1825.

19. Osinaike BB, Amanor-Boadu SD, Sanusi AA. Obstetric intensive care: a developing country experience. Internet J Anesthesiol. 2006;10(2):1-5.

20. Kuklina EV, Meikle SF, Jamieson DJ, Whiteman MK, Barfield WD, Hills SD. Severe obstetric morbidity in the United States 1998-2005. Obstet Gynecol. 2009;113(2 pt 1):293-9.

Cite this article as: Veerabhadrappa VK,

Shivanagappa M, Mahadevaiah M, Srikanth SM.

Maternal outcome in obstetric ICU and HDU: a study from a teaching hospital in South India. Int J Reprod Contracept Obstet Gynecol 2019;8:862-8. 